\title{
A Comparative Study of Atmospheric Moisture Recycling Rate between Observations and Models $\mathscr{O}$
}

\author{
Angela KaO, ${ }^{\text {a }}$ Xun JiAng, ${ }^{a}$ Liming Li, ${ }^{b}$ JAmes H. Trammell,${ }^{a}$ GuAng J. Zhang, ${ }^{c}$ \\ Hui Su, ${ }^{\mathrm{d}}$ JONATHAN H. JiAnG ${ }^{\mathrm{d}}$ AND YUK L. YunG ${ }^{\mathrm{e}}$ \\ ${ }^{\text {a }}$ Department of Earth and Atmospheric Sciences, University of Houston, Houston, Texas \\ ${ }^{\mathrm{b}}$ Department of Physics, University of Houston, Houston, Texas \\ ${ }^{\mathrm{c}}$ Climate, Atmospheric Science, and Physical Oceanography Division, Scripps Institution of Oceanography, La Jolla, California \\ ${ }^{\mathrm{d}}$ Science Division, Jet Propulsion Laboratory, California Institute of Technology, Pasadena, California \\ ${ }^{\mathrm{e}}$ Division of Geological and Planetary Sciences, California Institute of Technology, Pasadena, California
}

(Manuscript received 22 June 2017, in final form 20 October 2017)

\begin{abstract}
Precipitation and column water vapor data from 13 CMIP5 models and observational datasets are used to analyze atmospheric moisture recycling rate from 1988 to 2008. The comparisons between observations and model simulations suggest that most CMIP5 models capture two main characteristics of the recycling rate: 1) long-term decreasing trend of the global-average maritime recycling rate (atmospheric recycling rate over ocean within $60^{\circ} \mathrm{S}-60^{\circ} \mathrm{N}$ ) and 2) dominant spatial patterns of the temporal variations of the recycling rate (i.e., increasing in the intertropical convergence zone and decreasing in subtropical regions). All models, except one, successfully simulate not only the long-term trend but also the interannual variability of column water vapor. The simulations of precipitation are relatively poor, especially over the relatively short time scales, which lead to the discrepancy of the recycling rate between observations and the CMIP5 models. Comparisons of spatial patterns also suggest that the CMIP5 models simulate column water vapor better than precipitation. The comparative studies indicate the scope of improvement in the simulations of precipitation, especially for the relatively short-time-scale variations, to better simulate the recycling rate of atmospheric moisture, an important indicator of climate change.
\end{abstract}

\section{Introduction}

Observational studies suggest that the total mass of water vapor increases as a response to the increase in temperature (Trenberth et al. 2005; Wentz et al. 2007; Santer et al. 2007). Similar trends are also seen in the total mass of water vapor from models (Bosilovich et al. 2005; Held and Soden 2006). Unlike the simple relationship between water vapor and temperature, the variations of precipitation are more complex (Trenberth and Shea 2005; Adler et al. 2008; Allan and Soden 2008; Liu et al. 2009; Li et al. 2011; Trammell et al. 2016). On a regional scale, it was found that precipitation increases (decreases) in the wet (dry)

Supplemental information related to this paper is available at the Journals Online website: https://doi.org/10.1175/JCLI-D-170421.s1.

Corresponding author: Xun Jiang, xjiang7@uh.edu areas (Chou and Neelin 2004; Neelin et al. 2006; Allan and Soden 2007; Chou et al. 2009; Li et al. 2011; Durack et al. 2012; Polson et al. 2013; Chou et al. 2013; Trammell et al. 2015; Kao et al. 2017). On a global scale, there is a weak positive trend in the precipitation, with large discrepancies among different studies (Allen and Ingram 2002; Adler et al. 2003; Trenberth et al. 2003; Held and Soden 2006; Gu et al. 2007; Stephens and Ellis 2008; Adler et al. 2008; Liepert and Previdi 2009; Trenberth 2011; Zhou et al. 2011). Recent observational studies (Allan et al. 2010; Li et al. 2011) further suggest that the trend of global water vapor is stronger than the trend of global precipitation, which is consistent with results from some theoretical and model studies (Stephens and Ellis 2008; Allen and Ingram 2002; Emori and Brown 2005; Vecchi and Soden 2007; Richter and Xie 2008). Because the atmospheric water vapor increases faster than the precipitation over the global domain, it suggests that water recycles more slowly over the global domain ( $\mathrm{Li}$ et al. 2011). 
TABLE 1 . The linear trends ( $\%$ decade $\left.^{-1}\right)$ and corresponding confidence levels of maritime recycle rate $R$, maritime precipitation $P$, and maritime water vapor $W$ (1988-2008; shown in Figs. 1-3). Confidence levels are listed in parentheses. (Acronym expansions are available online at http://www.ametsoc.org/PubsAcronymList.)

\begin{tabular}{|c|c|c|c|}
\hline & $R$ & $P$ & $W$ \\
\hline Recycling rate & $-0.63 \pm 0.40(88.4 \%)$ & - & - \\
\hline GPCP & - & $0.31 \pm 0.48(<80 \%)$ & - \\
\hline $\mathrm{SSM} / \mathrm{I}$ & - & - & $0.90 \pm 0.33(99.3 \%)$ \\
\hline $\begin{array}{l}\text { NCAR Community Atmosphere Model, } \\
\text { version } 5 \text { (CAM5) }\end{array}$ & $-1.37 \pm 0.33(99.9 \%)$ & $-0.40 \pm 0.37(<80 \%)$ & $0.92 \pm 0.35(99.2 \%)$ \\
\hline $\begin{array}{l}\text { Canadian Centre for Climate Modelling } \\
\text { and Analysis (CCma; CanESM2) }\end{array}$ & $-0.55 \pm 0.33(90.4 \%)$ & $0.18 \pm 0.28(<80 \%)$ & $1.07 \pm 0.37(99.6 \%)$ \\
\hline $\begin{array}{l}\text { Centre National de Recherches } \\
\text { Météorologiques (CNRM-CM5) }\end{array}$ & $-0.97 \pm 0.22(99.9 \%)$ & $0.23 \pm 0.24(<80 \%)$ & $0.93 \pm 0.36(99.1 \%)$ \\
\hline $\begin{array}{l}\text { Commonwealth Scientific and Industrial } \\
\text { Research Organisation (CSIRO Mk3.6.0) }\end{array}$ & $-0.69 \pm 0.21(99.9 \%)$ & $-0.05 \pm 0.30(<80 \%)$ & $0.88 \pm 0.33(99.2 \%)$ \\
\hline $\begin{array}{l}\text { Geophysical Fluid Dynamics Laboratory } \\
\text { (GFDL CM3) }\end{array}$ & $-1.08 \pm 0.30(99.9 \%)$ & $-0.16 \pm 0.39(<80 \%)$ & $1.07 \pm 0.32(99.9 \%)$ \\
\hline $\begin{array}{l}\text { NASA Goddard Institute for Space Studies } \\
\text { (GISS-E2-R) }\end{array}$ & $-0.59 \pm 0.23(99.0 \%)$ & $0.02 \pm 0.17(<80 \%)$ & $0.59 \pm 0.30(95.0 \%)$ \\
\hline Institute of Numerical Mathematics (INM-CM4.0) & $-0.46 \pm 0.21(97.2 \%)$ & $0.11 \pm 0.29(<80 \%)$ & $0.76 \pm 0.30(98.9 \%)$ \\
\hline L’Institut Pierre-Simon Laplace (IPSL-CM5A) & $-0.67 \pm 0.40(90.6 \%)$ & $0.15 \pm 0.25(<80 \%)$ & $1.04 \pm 0.36(99.6 \%)$ \\
\hline $\begin{array}{l}\text { Model for Interdisciplinary Research on Climate, } \\
\text { version } 5 \text { (MIROC5) }\end{array}$ & $-1.29 \pm 0.33(99.9 \%)$ & $-0.02 \pm 0.35(<80 \%)$ & $1.09 \pm 0.36(99.7 \%)$ \\
\hline Met Office Hadley Centre (MOHC; HadGEM2-ES) & $-0.79 \pm 0.22(99.9 \%)$ & $0.34 \pm 0.24(84 \%)$ & $0.98 \pm 0.26(99.9 \%)$ \\
\hline Max Planck Institute (MPI-ESM-LR) & $-0.84 \pm 0.30(99.5 \%)$ & $0.24 \pm 0.26(<80 \%)$ & $0.98 \pm 0.27(99.9 \%)$ \\
\hline Meteorological Research Institute (MRI-CGCM3) & $-0.40 \pm 0.26(87.5 \%)$ & $0.38 \pm 0.40(<80 \%)$ & $0.83 \pm 0.30(99.4 \%)$ \\
\hline Norwegian Climate Centre (NCC; NorESM1-M) & $-0.76 \pm 0.25(99.7 \%)$ & $0.05 \pm 0.33(<80 \%)$ & $1.09 \pm 0.31(99.9 \%)$ \\
\hline
\end{tabular}

The recycling rate of atmospheric moisture $R$ (Chahine et al. 1997; $\mathrm{Li}$ et al. 2011) is defined as a ratio between precipitation $P$ and column water vapor $W$. Because it includes both precipitation and column water vapor, the recycling rate can be used to monitor the variations in the hydrological cycle. The percentage change of the recycling rate $(\Delta R / \bar{R}$, where the ovebar denotes the mean) is equal to the difference between the percentage change of precipitation $(\Delta P / \bar{P})$ and the percentage change of column water vapor $(\Delta W / \bar{W})(\mathrm{Li}$ et al. 2011). The recycling rate percentage change $(\Delta R / \bar{R})$ is positive when the percentage change of precipitation $(\Delta P / \bar{P})$ is larger than the percentage change of column water vapor $(\Delta W / \bar{W})$, and vice versa. Some theoretical and observational studies have been conducted to explore the recycling rate and related parameters for measuring the intensity of the hydrological cycle (Chahine et al. 1997; Trenberth 1998; Stephens and Ellis 2008; Li et al. 2011). However, a comparative study of the recycling rates between observations and numerical simulations has not been carried out. In this study, we will examine how well the models simulate the temporal and spatial variations of the recycling rate.

\section{Data and models}

To explore the temporal variations of the recycling rate, the latest datasets from the Special Sensor
Microwave Imager (SSM/I) (Wentz 1997; Wentz and Spencer 1998; Wentz and Meissner 2007; Hilburn and Wentz 2008) and the Global Precipitation Climatology Project (GPCP) (Huffman et al. 2009, 2012; Adler et al. 2012) are utilized in this paper. The dataset of SSM/I version 6 (V6) has water vapor over the ocean from 1988 to present, with a spatial resolution of $0.25^{\circ} \times 0.25^{\circ}$ (latitude by longitude). The latest version of GPCP, version 2.3 (V2.3), has the global precipitation data from 1979 to present, with a spatial resolution of $2.5^{\circ} \times 2.5^{\circ}$ (latitude by longitude). Rain gauge, satellite, and sounding data are utilized to produce GPCP monthly precipitation data. GPCP V2.3 precipitation data are provided by the NOAA Office of Oceanic and Atmospheric Research (OAR) and Earth System Research Laboratory (ESRL) Physical Sciences Division (PSD) (available online at https://www.esrl.noaa.gov/psd/data/ gridded/data.gpcp.html). The SSM/I V6 water vapor data are provided by Remote Sensing Systems (available online at http://www.remss.com/missions/ ssmi/). Monthly mean data from SSM/I and GPCP are used in this paper.

Precipitation and column water vapor from phase 5 of the Coupled Model Intercomparison Project (CMIP5) (Taylor et al. 2012) model simulations are used in the paper to explore the simulation of recycling rates from different models. Observed sea surface temperature is used in the AMIP-type CMIP5 model simulations to 

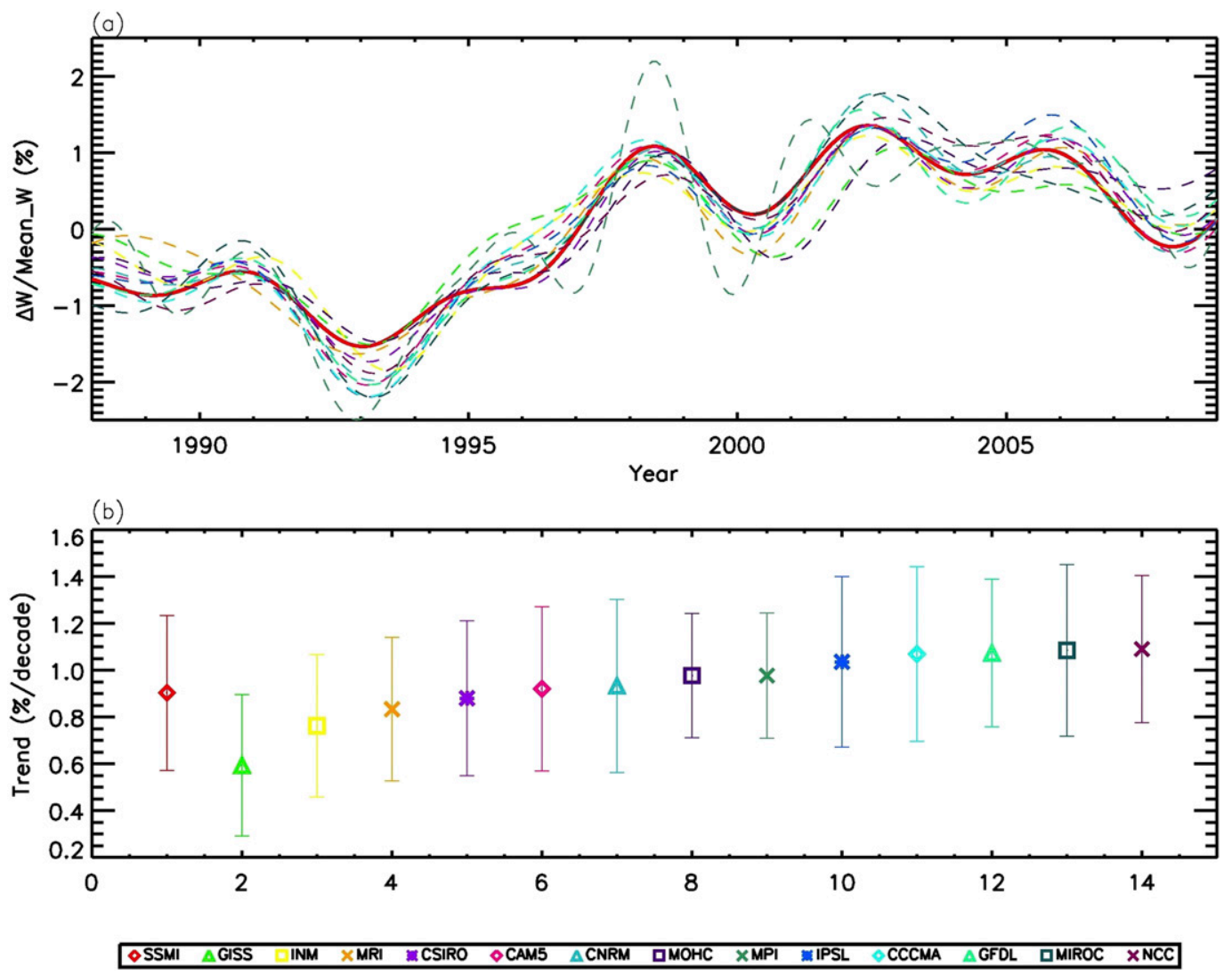

FIG. 1. (a) Temporal variations of low-pass-filtered column water vapor averaged over ocean between $60^{\circ} \mathrm{N}$ and $60^{\circ} \mathrm{S}$. Red solid line is low-pass-filtered SSM/I column water vapor time series. Color dashed lines are low-passfiltered column water vapor time series from CMIP5 models. (b) Trends and uncertainties for low-pass-filtered maritime column water vapor time series from SSM/I and CMIP5 models.

drive the models (Taylor et al. 2012). There are 13 CMIP5 models: CAM5, CanESM2, CNRM-CM5, CSIRO Mk3.6.0, GFDL CM3, GISS-E2-R, INMCM4.0, IPSL-CM5A, MIROC5, HadGEM2-ES, MPIESM-LR, MRI-CGCM3, and NorESM1-M (see Table 1 for the institutions associated with the model acronyms). The tropical cloud, moisture, and precipitation fields in these models have been validated extensively against observations (e.g., Jiang et al. 2012; Tian et al. 2013; Stanfield et al. 2016). Because most model simulations ended in 2008, we focus on the variations of the recycling rate from both observations and model simulations from January 1988 to December 2008.

\section{Results}

Because of the lack of long-term continuous data of water vapor over land and the poor data quality in the polar region as a result of limited in situ measurements to validate the satellite data, the observation results will be compared with model simulations over ocean within $60^{\circ} \mathrm{S}-60^{\circ} \mathrm{N}$. Since the recycling rate is related to column water vapor and precipitation, we first explore the temporal variations of maritime column water vapor and precipitation within $60^{\circ} \mathrm{S}-60^{\circ} \mathrm{N}$. Figure 1 shows the comparison of temporal variations of maritime column water vapor between the observation and model simulations averaged over $60^{\circ} \mathrm{S}-60^{\circ} \mathrm{N}$ from 1988 to 2008 . El Niño-Southern Oscillation (ENSO) signals have been removed from the time series by a multiple regression method based on the Niño-3.4 index (Li et al. 2011). A low-pass filter is applied to all time series to remove the high-frequency signals, and only signals with periods longer than $3 \mathrm{yr}$ are kept (Jiang et al. 2004). There is an anomaly around 1996-98, which is related to the Pacific decadal variability (Gu and Adler 2013). Gu and Adler (2013) suggest that both Pacific decadal variability and global warming can contribute to the long-term trend in water vapor. The maritime SSM/I water vapor has a strong positive trend of $0.90 \pm 0.33 \%$ decade $^{-1}$ over 1988-2008. The linear trend $b$ is estimated using the least squares fitting. The standard error of the linear trend 

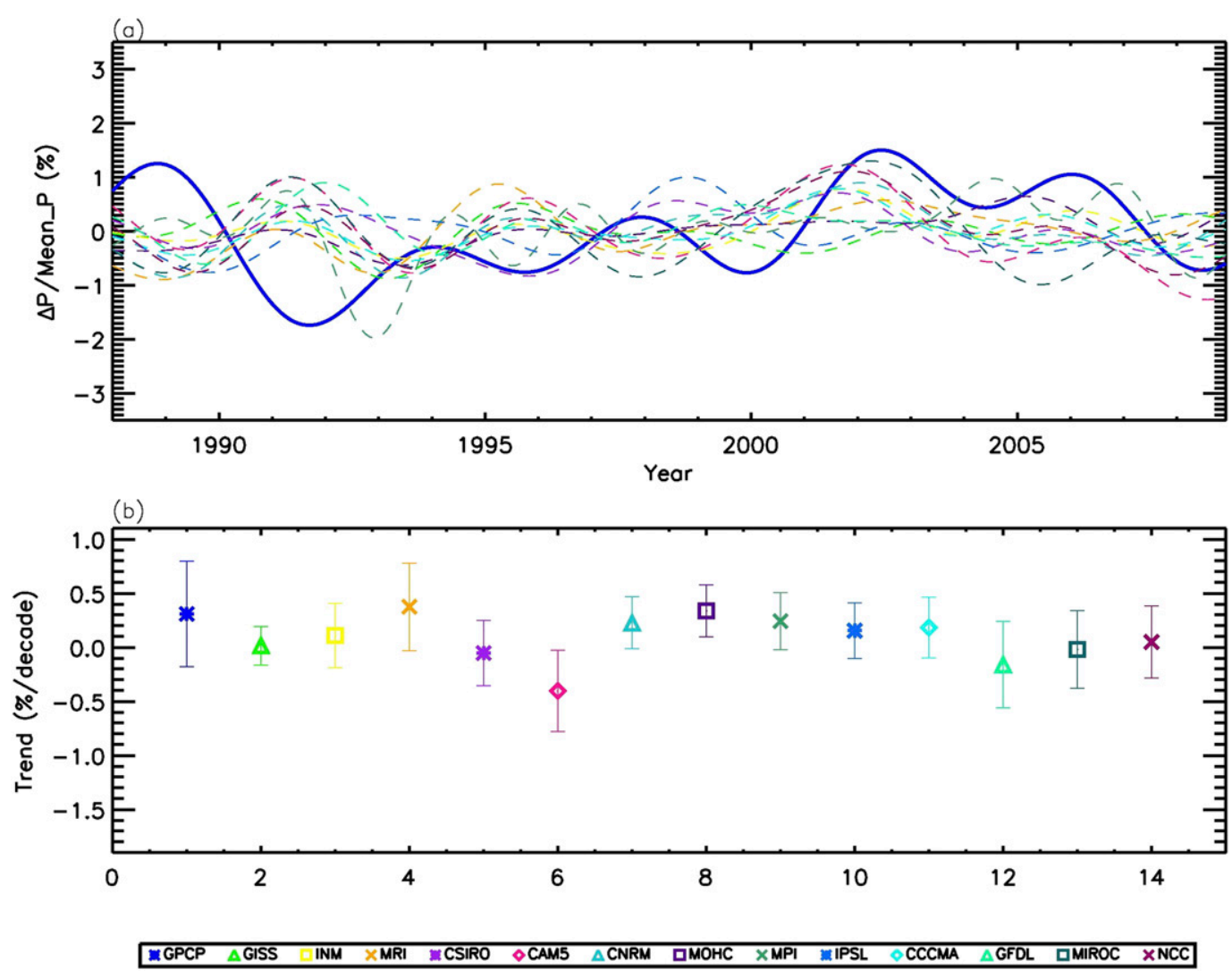

FIG. 2. (a) Temporal variations of low-pass-filtered precipitation averaged over ocean between $60^{\circ} \mathrm{N}$ and $60^{\circ} \mathrm{S}$. Blue solid line is low-pass-filtered GPCP precipitation time series. Color dashed lines are low-pass-filtered precipitation time series from CMIP5 models. (b) Trends and uncertainties for low-pass-filtered maritime precipitation time series from GPCP and CMIP5 models.

$\operatorname{SE}(b)$ is calculated by $\operatorname{SE}(b)=\left(s / \sqrt{N_{1}}\right) / \sqrt{\left(1 / N_{2}\right) \operatorname{sum}\left(x_{i}^{2}\right)}$, where $s$ is the standard deviation of the data, $N_{1}$ is the number of degrees of freedom of the data, $N_{2}$ is the length of the dataset, and $x_{i}$ is the time series (Bevington and Robinson 2003; Li et al. 2011). The $t$ statistics, defined by $t=|b / \mathrm{SE}(b)|$, are used to estimate the confidence level of the trend (Box et al. 2005; Li et al. 2011). Details for trends of maritime column water vapor from observation and models are summarized in Table 1. All models demonstrate significant positive trends of maritime column water vapor with a range from $0.59 \%$ to $1.09 \%$ decade $^{-1}$, which are within the range of the trend of SSM/I maritime column water vapor $(0.90 \pm 0.33 \%$ decade $^{-1}$ ). All but one model (MPI-ESM-LR) successfully simulate not only the long-term trend but also the interannual variability of column water vapor.

Figure 2 displays the temporal variations of maritime precipitation between the observation and model simulations averaged over $60^{\circ} \mathrm{S}-60^{\circ} \mathrm{N}$ from 1988 to 2008 . The linear trend of GPCP maritime precipitation is 0.31 $\pm 0.48 \%$ decade $^{-1}$, which is very weak and not statistically significant. The linear trends of model maritime precipitation demonstrate a relatively large range, from $-0.40 \%$ to $0.37 \%$ decade $^{-1}$. Figure 2 and Table 1 suggest that most models have weak trends in maritime precipitation with large uncertainties, which are qualitatively consistent with the long-term temporal trend from the observation. However, Fig. 2 shows that there are large discrepancies at the relatively short time scales between the observation and the models. Therefore, the temporal variations of precipitation at the relatively short time scales should be explored in the future, when better models are available.

The insignificant, weak temporal trends in precipitation (Fig. 2) and the significant positive trends in column water vapor (Fig. 1) suggest that the maritime recycling rate (i.e., ratio of precipitation to water vapor) decreases with time. Figure 3 shows the comparison of temporal variations of the maritime recycling rates between observations and model simulations averaged over $60^{\circ} \mathrm{S}-60^{\circ} \mathrm{N}$ from 1988 to 2008 . The recycling rate is estimated as the ratio of the GPCP precipitation to SSM/I water vapor, which is shown as the blue solid line in Fig. 3a. Maritime mean recycling rate (blue solid line) 

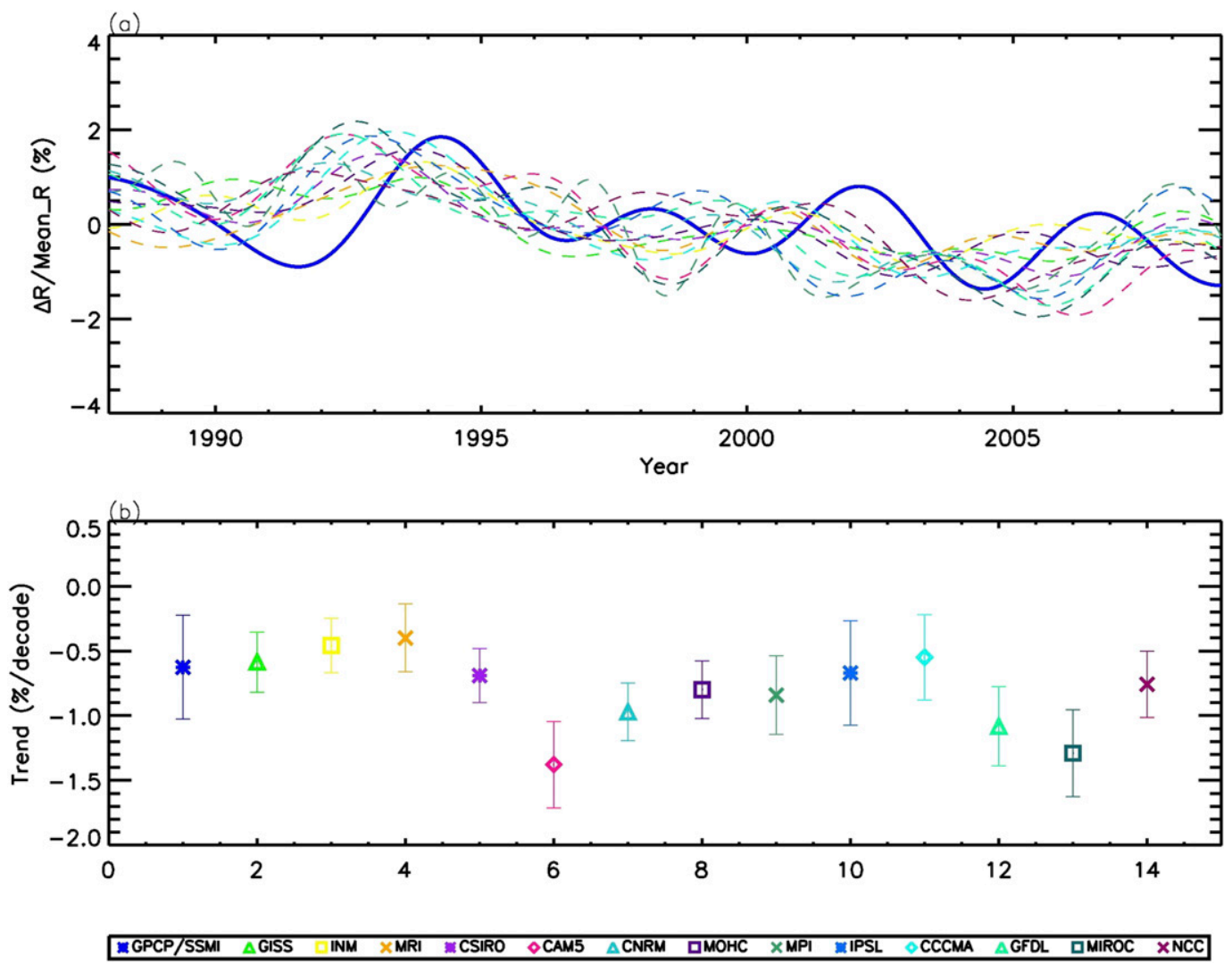

FIG. 3. (a) Temporal variations of low-pass-filtered recycling rate averaged over ocean between $60^{\circ} \mathrm{N}$ and $60^{\circ} \mathrm{S}$. Blue solid line is low-pass-filtered recycling rate (ratio of GPCP precipitation to SSM/I water vapor). Color dashed lines are low-pass-filtered recycling rate time series from CMIP5 models. (b) Trends and uncertainties for low-passfiltered maritime recycling rate time series from observations and CMIP5 models.

demonstrates a negative trend of $-0.63 \% \pm 0.40 \%$ decade $^{-1}$ over the past two decades. The negative trend in the maritime recycling rate suggests that the maritime precipitation increases more slowly than the maritime column water vapor, which suggests that the hydrological cycle is recycling slower over $60^{\circ} \mathrm{S}-60^{\circ} \mathrm{N}$. Temporal variations of CMIP5 maritime recycling rates are also shown in Fig. 3a. Maritime recycling rates from CMIP5 model simulations all suggest negative trends of the maritime recycling rates, with a range between $-1.37 \%$ and $-0.40 \%$ decade $^{-1}$. Of the 13 models, CAM5 has the strongest negative trend in the maritime recycling rate. Although both observations and models suggest negative trends of the maritime recycling rates on a decadal scale, they differ significantly in relatively short-term interannual variations.

Because the long-term column water vapor data are not available over the land, we cannot compare the global total column water and recycling rate between observations and models. Instead, we compare temporal variations of column water vapor, precipitation, and the recycling rate over both land and ocean between $60^{\circ} \mathrm{S}$ and $60^{\circ} \mathrm{N}$ from $13 \mathrm{CMIP} 5$ models. Results are shown in Figs. S1-S3 in the supplemental material. Temporal variations, trends, and uncertainties of column water vapor averaged over land and ocean from 13 CMIP5 models are shown in Fig. S1. All models demonstrate increasing trends of column water vapor for the global domain including both land and ocean. We also explore precipitation over both land and ocean from the 13 CMIP5 models in Fig. S2. Global model precipitation demonstrates weaker trends than the global model column water vapor, which is consistent with the results over ocean only. Additionally, as shown in Fig. S2, model simulations show a much better consistency in simulating precipitation trends when data over land are included, implying models have large discrepancies over ocean in simulating precipitation. Figure S3 demonstrates the temporal variations of the recycling rate from 13 CMIP5 models over both land and ocean at $60^{\circ} \mathrm{S}-$ $60^{\circ} \mathrm{N}$. The recycling rates of model simulations covering both land and ocean also demonstrate strong negative trends. The models consistently show that the global recycling rate is slowing down. 

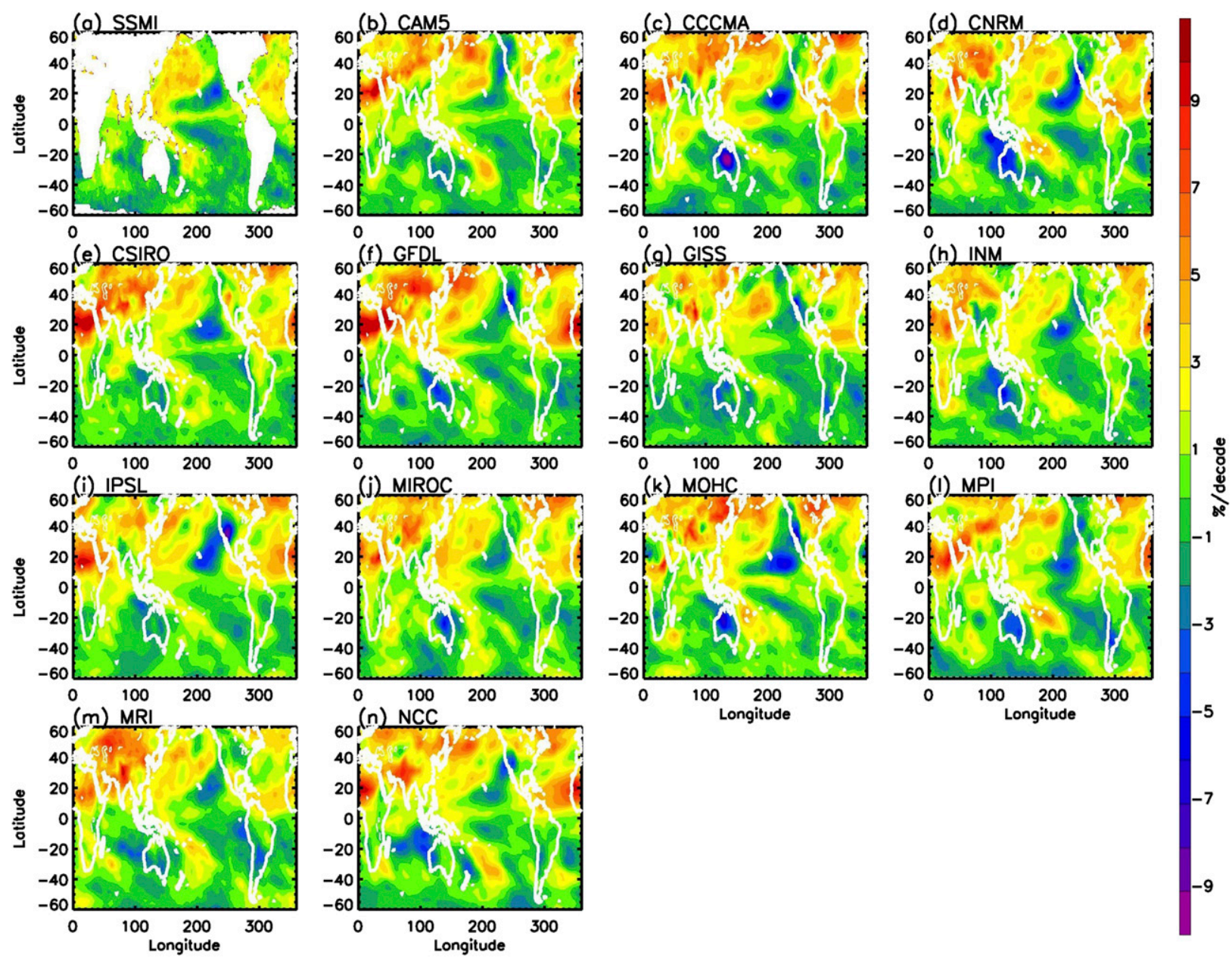

FIG. 4. Spatial patterns of temporal variation of water vapor $\left(\Delta W / \bar{W} ; \% \mathrm{decade}^{-1}\right)$ over the time period of $1988-2008$ from (a) SSM/I and (b)-(n) CMIP5 models. Color represents the ratio of temporal variation to time mean during one decade.

In addition to the temporal variations, we also explore the spatial patterns of temporal variations of column water vapor, precipitation, and the recycling rate. Figures 4 and 5 display the spatial patterns of temporal variations of column water vapor and precipitation between the observation and model simulations. The corresponding $90 \%$ confidence level areas are shown in Figs. S4 and S5 in the supplemental material. As shown in Fig. 4a, there are positive trends of water vapor over the northern Pacific and northern Atlantic Oceans and along the intertropical convergence zone (ITCZ), as seen in the SSM/I data. Most models can simulate positive trends in the column water vapor over the northern Pacific Ocean, northern Atlantic Ocean, and the ITCZ region, although a few models (e.g., INM-CM4.0, IPSLCM5A, MPI-ESM-LR, and MRI-CGCM3) do not simulate the positive trends well in the ITCZ. As shown in Fig. 5a, there are positive trends of precipitation over the ITCZ and storm-track regions and negative trends of precipitation over the subtropical regions, as seen from the GPCP precipitation. The strong positive trend of precipitation over the equatorial central and eastern Pacific ITCZ, flanked by negative trends of precipitation over the subtropics, may be a manifestation of the narrowing of the ITCZ in response to global warming (Wodzicki and Rapp 2016; Su et al. 2017). It should be cautioned that the underestimation of light rain over the subtropical ocean in the GPCP dataset (Burdanowitz et al. 2015) possibly affects the results of linear trends of precipitation in the subtropical ocean. Most of the models have captured the pattern that shows the positive percentage change of precipitation over the ITCZ and negative percentage change over the subtropical areas. In addition, the observational data are showing a significant increase over the ITCZ, where some models do not have as intense signals as the observations. The CAM5, CSIRO Mk3.6.0, GFDL CM3, and HadGEM2ES models show similar strong percentage change as the 

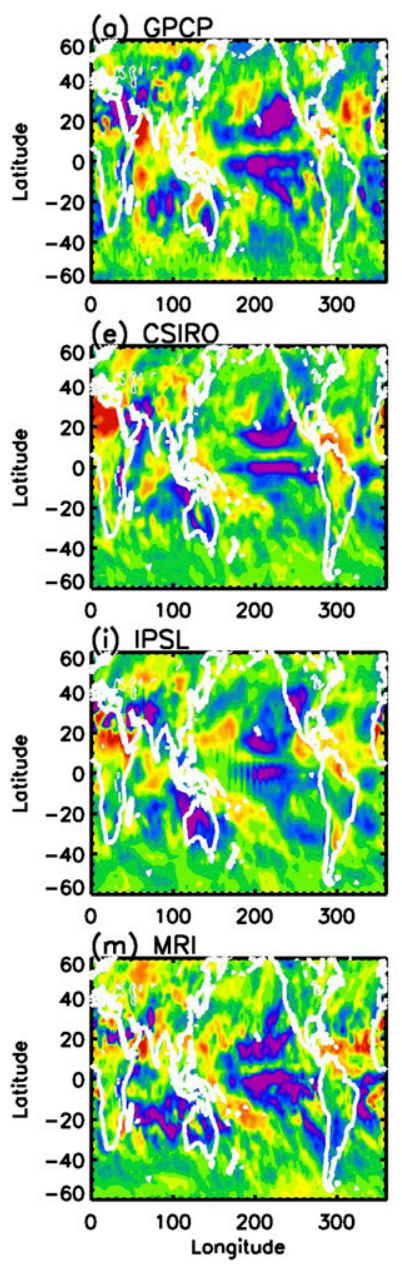
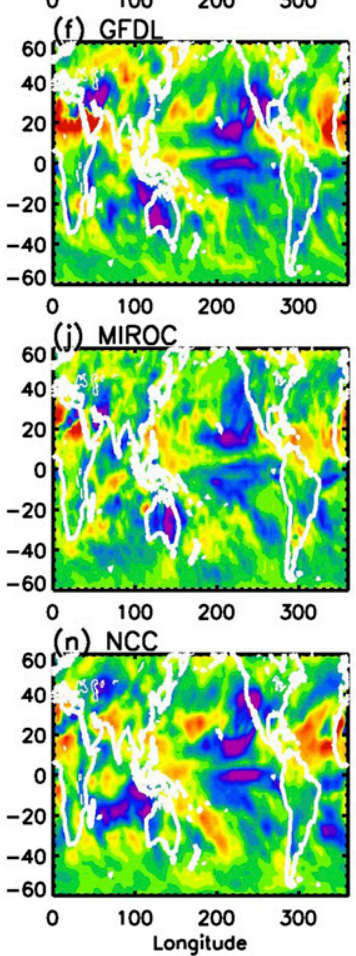
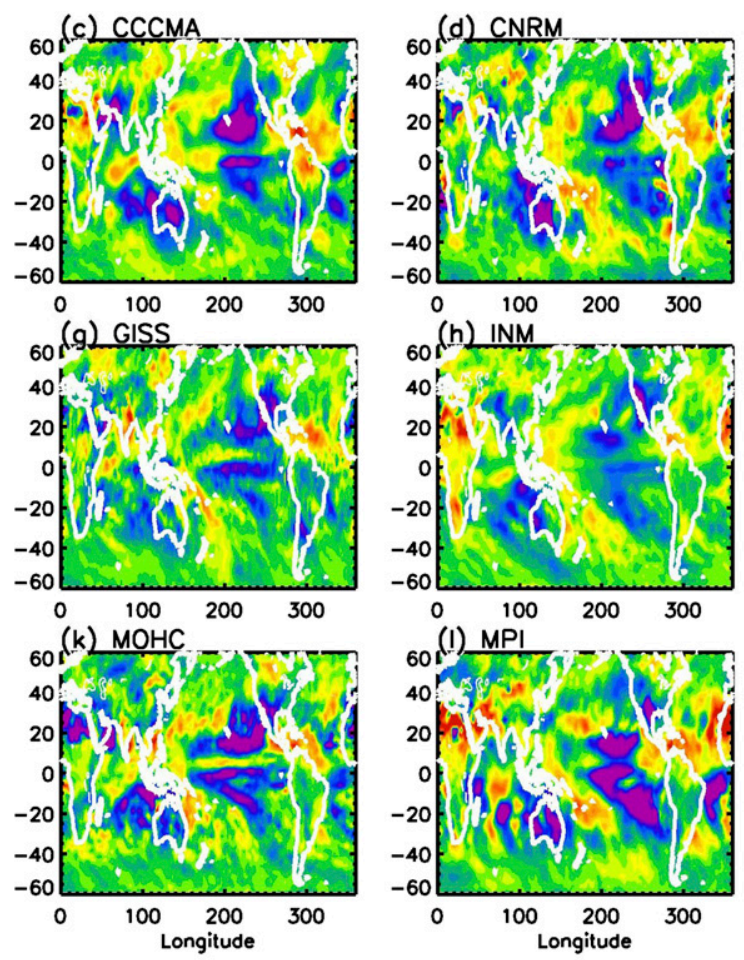

27

21
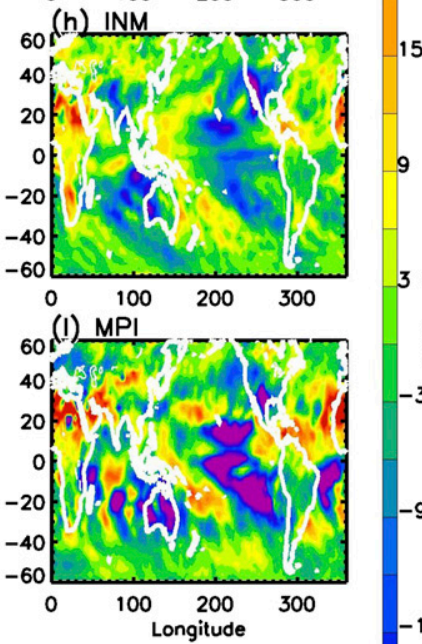

FIG. 5. Spatial patterns of temporal variation of precipitation $\left(\Delta P / \bar{P} ; \%\right.$ decade $\left.{ }^{-1}\right)$ over the time period of $1988-2008$ from (a) GPCP and (b)-(n) CMIP5 models. Color represents the ratio of temporal variation to time mean during one decade.

observations, whereas the INM-CM4.0 model is particularly weak. Most of the models underestimate the intensity of negative precipitation trends over the subtropical areas.

Figure 6 shows the spatial patterns of temporal variation of recycling rates over 1988-2008 from observations and models. The corresponding confidence levels of recycling rate trends larger than $90 \%$ are shown in Fig. S6 in the supplemental material. As shown in Fig. 6a, the temporal variations of the recycling rate are positive over the ITCZ and storm-track regions, which suggest the recycling rate of atmospheric moisture has intensified over these regions. Over these regions, the percentage change of the precipitation is larger than that of the column water vapor. As a result, the recycling rate is positive over the ITCZ and storm-track regions, which suggests the hydrological cycle is recycling faster over these regions. The recycling rate displays negative temporal variations over the subtropical regions as a result of a stronger negative trend in the precipitation than in the column water vapor, which suggests that the recycling rate of atmospheric moisture has slowed down in these regions. There are positive recycling rates over the ITCZ regions from most models, although a few models (e.g., CNRM-CM5, INM-CM4.0, MPI-ESMLR, and NorESM1-M) do not simulate the positive recycling rates well in the tropical Pacific regions. Most models can simulate the positive recycling rate over the high latitudes, although they have difficulties in simulating the locations of the storm tracks. CanESM2, MPI-ESM-LR, and MRI-CGCM3 tend to simulate the negative recycling rates better than the other models over the subtropical areas. It should be mentioned that the physics of the local recycling rate is more complicated than that of the global-mean recycling rate. The temporal variations of the regional recycling rate are determined by the temporal variations of regional precipitation and water vapor (Figs. 4 and 5, respectively), 

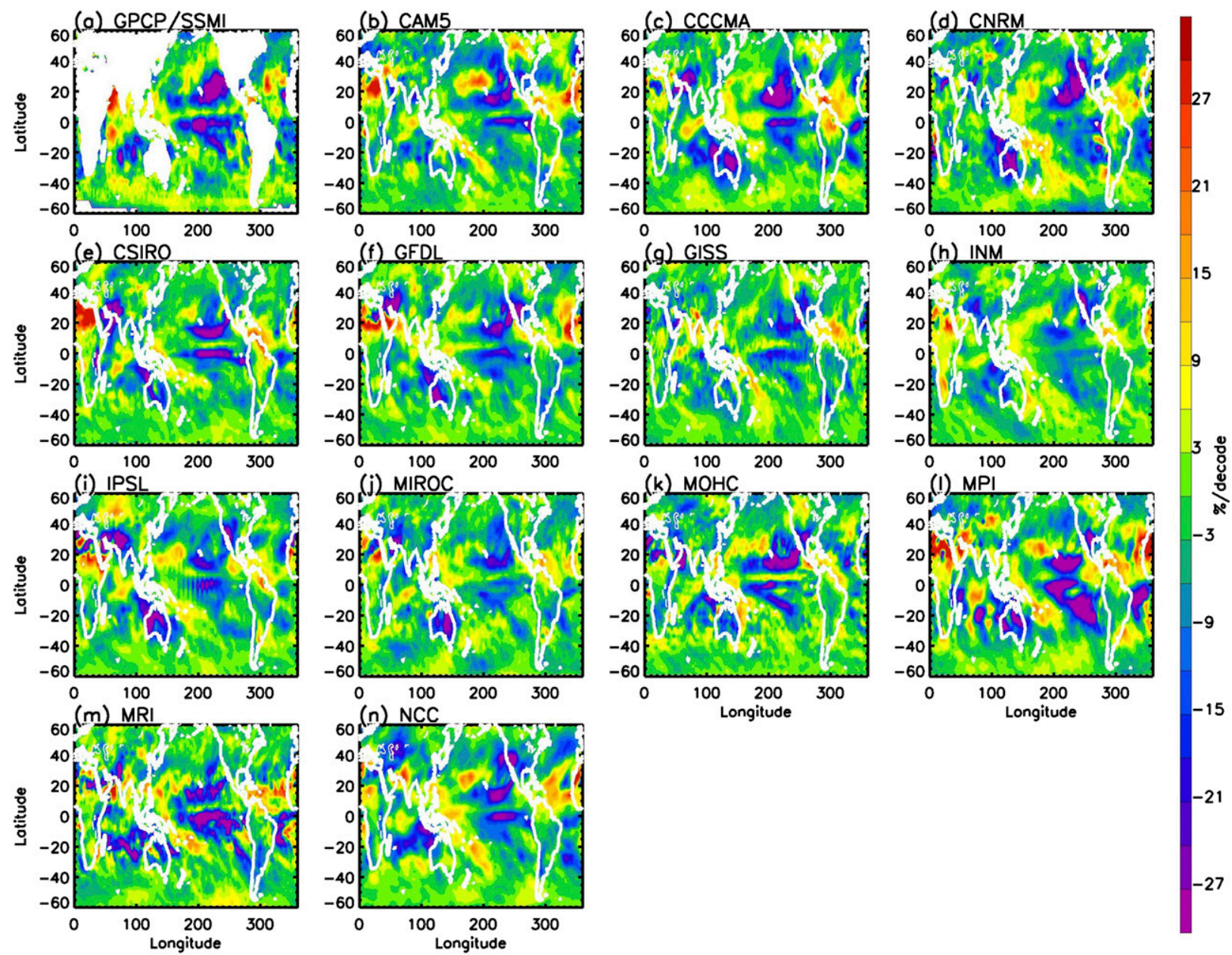

FIG. 6. Spatial patterns of temporal variation of recycling rate $\left(\Delta R / \bar{R}\right.$; \% decade $\left.{ }^{-1}\right)$ over the time period of $1988-2008$ from observations and models: (a) recycling rate based on GPCP precipitation and SSM/I water vapor and (b)-(n) recycling rate based on CMIP5 precipitation and water vapor.

which are strongly influenced by the divergence and convergence of water vapor associated with horizontal motions.

The trend of the global recycling rate is mainly affected by the trend of water vapor, whereas the trend of the local recycling rate is mainly affected by the trend of precipitation. As shown in Fig. 5, precipitation displays strong and significant trends in different regions. However, different regions demonstrate different and even opposite trends, so the global-average trend of precipitation is not strong and significant. On the other hand, the global water vapor demonstrates strong and significant trend; it is mainly affected by the global temperature via the Clausius-Clapeyron relation. Therefore, the trend of the global recycling rate is dominated by the significant trend of global water vapor. However, the linear trends of regional water vapor are weaker than the regional precipitation trends, as shown in Figs. 4 and 5, and that is why the regional recycling rate is mainly affected by precipitation instead of water vapor.

\section{Conclusions}

Precipitation data from GPCP and column water vapor data from SSM/I are combined with CMIP5 models to explore the recycling rate from 1988 to 2008. Both observations and models suggest a negative trend of maritime mean recycling rate, which is a result of a weaker trend in the maritime mean precipitation than the mean column water vapor. Overall, all the models simulate similar trends to the observations. The models show consistent trends of maritime mean recycling rate with the observations. On a regional scale, the simulated spatial patterns of the recycling rate capture the dominant features in the temporal variations of the recycling rates: positive trend of the recycling rate over the ITCZ 
and storm tracks and negative trend of the recycling rate over the subtropical dry areas. This suggests that the CMIP5 models approximately capture the regional- and global-scale recycling rate variations.

The comparisons between observations and simulations also reveal a large discrepancy in the interannual variations of the maritime recycling rate. The analyses of simulations of maritime precipitation and maritime column water vapor further suggest that the discrepancy of the maritime recycling rate is mainly from the poor simulations of maritime precipitation, which suggests that the simulations of relatively short-term variations of precipitation need improvement to better capture the recycling rate of atmospheric moisture. The improved simulations of the recycling rate will help us better understand the physics that govern the temporal variation of hydrological cycle.

Acknowledgments. XJ and YLY were supported by NASA Grants NNX13AC04G and NNX13AK34G. HS and JHJ acknowledge the funding support from NASA NEWS project. HS and JHJ conducted the work at the Jet Propulsion Laboratory, under contract with NASA. LL was supported by NASA ROSES NNH15ZDA001N-PDART program. GJZ was supported by National Science Foundation Grant AGS1549259. GPCP V2.3 data are provided by the center of Earth System Research Laboratory (http://www.esrl. noaa.gov/psd/data/gridded/data.gpcp.html). SSM/I data are provided by the center of Remote Sensing Systems (http://www.SSM/I.com/SSM/I/SSM/I_browse.html). The authors declare no competing financial interest.

\section{REFERENCES}

Adler, R. F., and Coauthors, 2003: The Version-2 Global Precipitation Climatology Project (GPCP) monthly precipitation analysis (1979-present). J. Hydrometeor., 4, 1147-1167, https://doi.org/10.1175/1525-7541(2003)004<1147: TVGPCP $>2.0 . C O ; 2$.

—, G. J. Gu, J.-J. Wang, G. J. Huffman, S. Curtis, and D. Bolvin, 2008: Relationships between global precipitation and surface temperature on interannual and longer timescales (1979-2006). J. Geophys. Res., 113, D22104, https://doi.org/10.1029/ 2008JD010536.

— , — , and G. J. Huffman, 2012: Estimating climatological bias errors for the Global Precipitation Climatology Project (GPCP). J. Appl. Meteor. Climatol., 51, 84-99, https://doi.org/ 10.1175/JAMC-D-11-052.1.

Allan, R. P., and B. J. Soden, 2007: Large discrepancy between observed and simulated precipitation trends in the ascending and descending branches of the tropical circulation. Geophys. Res. Lett., 34, L18705, https://doi.org/10.1029/2007GL031460.

_- and 2008: Atmospheric warming and the amplification of precipitation extremes. Science, 321, 1481-1484, https:// doi.org/10.1126/science.1160787.
,-- , V. O. John, W. Ingram, and P. Good, 2010: Current changes in tropical precipitation. Environ. Res. Lett., 5, 025205, https://doi.org/10.1088/1748-9326/5/2/025205.

Allen, M. R., and W. J. Ingram, 2002: Constraints on future changes in climate and the hydrological cycle. Nature, 419, 224-232, https://doi.org/10.1038/nature01092.

Bevington, P. R., and D. K. Robinson, 2003: Data Reduction and Error Analysis for the Physical Sciences. 3rd ed. McGraw-Hill, $320 \mathrm{pp}$.

Bosilovich, M. G., S. D. Schubert, and G. K. Walker, 2005: Global changes of the water cycle intensity. J. Climate, 18, 1591-1608, https://doi.org/10.1175/JCLI3357.1.

Box, G. E. P., J. S. Hunter, and W. G. Hunter, 2005: Statistics for Experimenters: Design, Innovation, and Discovery. 2nd ed. John Wiley \& Sons, 664 pp.

Burdanowitz, J., L. Nuijens, and B. Stevens, 2015: Evaluating light rain from satellite- and ground-based remote sensing data over the subtropical North Atlantic. J. Appl. Meteor. Climatol., 54, 556-572, https://doi.org/10.1175/JAMC-D-14-0146.1.

Chahine, M. T., R. Haskins, and E. Fetzer, 1997: Observation of the recycling rate of moisture in the atmosphere: 1988-1994. GEWEX News, Vol. 7, International GEWEX Project Office, Southampton, United Kingdom, 1-4.

Chou, C., and J. D. Neelin, 2004: Mechanisms of global warming impacts on regional tropical precipitation. J. Climate, 17, 2688-2701, https://doi.org/10.1175/1520-0442(2004)017<2688: MOGWIO $>2.0 . \mathrm{CO} ; 2$.

_ - C C.-A. Chen, and J.-Y. Tu, 2009: Evaluating the "richget-richer" mechanism in tropical precipitation change under global warming. J. Climate, 22, 1982-2005, https://doi.org/ 10.1175/2008JCLI2471.1.

, J. C. H. Chiang, C.-W. Lan, C.-H. Chung, Y.-C. Liao, and C.-J. Lee, 2013: Increase in the range between wet and dry season precipitation. Nat. Geosci., 6, 263-267, https://doi.org/ 10.1038/ngeo1744.

Durack, P. J., S. E. Wijffels, and R. J. Matear, 2012: Ocean salinities reveal strong global water cycle intensification during 1950 to 2000. Science, 336, 455-458, https://doi.org/10.1126/ science.1212222.

Emori, S., and S. J. Brown, 2005: Dynamic and thermodynamic changes in mean and extreme precipitation under changed climate. Geophys. Res. Lett., 32, L17706, https://doi.org/ 10.1029/2005GL023272.

Gu, G. J., and R. F. Adler, 2013: Interdecadal variability/longterm changes in global precipitation patterns during the past three decades: Global warming and/or Pacific decadal variability? Climate Dyn., 40, 3009-3022, https://doi.org/10.1007/ s00382-012-1443-8.

— _ _ G. J. Huffman, and S. Curtis, 2007: Tropical rainfall variability on interannual-to-interdecadeal and longer time scales derived from the GPCP monthly product. J. Climate, 20, 4033-4046, https://doi.org/10.1175/JCLI4227.1.

Held, I. M., and B. J. Soden, 2006: Robust responses of the hydrological cycle to global warming. J. Climate, 19, 5686-5699, https://doi.org/10.1175/JCLI3990.1.

Hilburn, K. A., and F. J. Wentz, 2008: Intercalibrated passive microwave rain products from the Unified Microwave Ocean Retrieval Algorithm (UMORA). J. Appl. Meteor. Climatol., 47, 778-795, https://doi.org/10.1175/2007JAMC1635.1.

Huffman, G. J., R. F. Adler, D. T. Bolvin, and G. J. Gu, 2009: Improving the global precipitation record: GPCP version 2.1 . Geophys. Res. Lett., 36, L17808, https://doi.org/10.1029/ 2009GL040000. 
- D. T. Bolvin, and R. F. Adler, 2012: GPCP version 2.2 combined precipitation data set. NCDC Doc., $46 \mathrm{pp}$.

Jiang, J. H., and Coauthors, 2012: Evaluation of cloud and water vapor simulations in CMIP5 climate models using NASA "ATrain” satellite observations. J. Geophys. Res., 117, D14105, https://doi.org/10.1029/2011JD017237.

Jiang, X., C. D. Camp, R. Shia, D. Noone, C. Walker, and Y. L. Yung, 2004: Quasi-biennial oscillation and quasibiennial oscillation-annual beat in the tropical total column ozone: A two-dimensional model simulation. J. Geophys. Res., 109, D16305, https://doi.org/10.1029/2003JD004377.

Kao, A., X. Jiang, L. Li, H. Su, and Y. Yung, 2017: Precipitation, circulation, and cloud variability over the past two decades. Earth Space Sci., 4, 597-606, https://doi.org/10.1002/2017EA000319.

Li, L., X. Jiang, M. T. Chahine, E. T. Olsen, E. J. Fetzer, L. Chen, and Y. L. Yung, 2011: The recycling rate of atmospheric moisture over the past two decades (1988-2009). Environ. Res. Lett., 6, 034018, https://doi.org/10.1088/1748-9326/6/3/034018.

Liepert, B. G., and M. Previdi, 2009: Do models and observations disagree on the rainfall response to global warming? J. Climate, 22, 3156-3166, https://doi.org/10.1175/2008JCLI2472.1.

Liu, S. C., C. B. Fu, C.-J. Shiu, J.-P. Chen, and F. T. Wu, 2009: Temperature dependence of global precipitation extremes. Geophys. Res. Lett., 36, L17702, https://doi.org/10.1029/ 2009GL040218.

Neelin, J. D., M. Münnich, H. Su, J. E. Meyerson, and C. E. Holloway, 2006: Tropical drying trends in global warming models and observations. Proc. Natl. Acad. Sci. USA, 103, 6110-6115, https://doi.org/10.1073/pnas.0601798103.

Polson, D., G. C. Hegerl, R. P. Allan, and B. Balan Sarojini, 2013: Have greenhouse gases intensified the contrast between wet and dry regions? Geophys. Res. Lett., 40, 4783-4787, https:// doi.org/10.1002/grl.50923.

Richter, I., and S.-P. Xie, 2008: Muted precipitation increase in global warming simulations: A surface evaporation perspective. J. Geophys. Res., 113, D24118, https://doi.org/10.1029/ 2008JD010561.

Santer, B. D., and Coauthors, 2007: Identification of humaninduced changes in atmospheric moisture content. Proc. Natl. Acad. Sci. USA, 104, 15248-15253, https://doi.org/ 10.1073/pnas.0702872104.

Stanfield, R. E., and Coauthors, 2016: A quantitative assessment of precipitation associated with the ITCZ in the CMIP5 GCM simulations. Climate Dyn., 47, 1863-1880, https://doi.org/ 10.1007/s00382-015-2937-y.

Stephens, G. L., and T. D. Ellis, 2008: Controls of global-mean precipitation increases in global warming GCM experiments. J. Climate, 21, 6141-6155, https://doi.org/10.1175/2008JCLI2144.1.

Su, H., and Coauthors, 2017: Tightening of tropical ascent and high clouds key to precipitation change in a warmer climate. Nat. Commun., 8, 15771, https://doi.org/10.1038/ncomms15771.

Taylor, K. E., R. J. Stouffer, and G. A. Meehl, 2012: An overview of CMIP5 and the experiment design. Bull. Amer. Meteor. Soc., 93, 485-498, https://doi.org/10.1175/BAMS-D-11-00094.1.
Tian, B., E. J. Fetzer, B. H. Kahn, J. Teixeira, E. Manning, and T. Hearty, 2013: Evaluating CMIP5 models using AIRS tropospheric air temperature and specific humidity climatology. J. Geophys. Res. Atmos., 118, 114-134, https://doi.org/10.1029/ 2012JD018607.

Trammell, J. H., X. Jiang, L. Li, M. Liang, M. Li, J. Zhou, E. Fetzer, and Y. Yung, 2015: Investigation of precipitation variations over wet and dry areas from observation and model. $A d v$. Meteor., 2015, 981092, https://doi.org/10.1155/2015/981092.

,,-- - A. Kao, G. J. Zhang, E. K. M. Chang, and Y. Yung, 2016: Temporal and spatial variability of precipitation from observations and models. J. Climate, 29, 2543 2555, https://doi.org/10.1175/JCLI-D-15-0325.1.

Trenberth, K. E., 1998: Atmospheric moisture residence times and cycling: Implications for rainfall rates and climate change. Climatic Change, 39, 667-694, https://doi.org/10.1023/ A:1005319109110.

- 2011: Changes in precipitation with climate change. Climate Res., 47, 123-138, https://doi.org/10.3354/cr00953.

_ , and D. J. Shea, 2005: Relationships between precipitation and surface temperature. Geophys. Res. Lett., 32, L14703, https://doi.org/10.1029/2005GL022760.

— A. Dai, R. M. Rasmussen, and D. B. Parsons, 2003: The changing character of precipitation. Bull. Amer. Meteor. Soc., 84, 1205-1217, https://doi.org/10.1175/BAMS-84-9-1205.

_ J. Fasullo, and L. Smith, 2005: Trends and variability in column-integrated atmospheric water vapor. Climate Dyn., 24, 741-758, https://doi.org/10.1007/s00382-005-0017-4.

Vecchi, G. A., and B. J. Soden, 2007: Global warming and the weakening of the tropical circulation. J. Climate, 20, 43164340, https://doi.org/10.1175/JCLI4258.1.

Wentz, F. J., 1997: A well-calibrated ocean algorithm for special sensor microwave/imager. J. Geophys. Res., 102, 8703-8718, https://doi.org/10.1029/96JC01751.

_ , and R. W. Spencer, 1998: SSM/I rain retrievals within a unified all-weather ocean algorithm. J. Atmos. Sci., 55, 16131627, https://doi.org/10.1175/1520-0469(1998)055<1613: SIRRWA $>2.0 . \mathrm{CO} ; 2$.

— , and T. Meissner, 2007: Supplement 1: Algorithm theoretical basis document for AMSR-E ocean algorithms. RSS Tech. Rep. 051707, 6 pp., http://images.remss.com/papers/rsstech/ 2007_051707_Wentz_AMSR_Ocean_V2_Supplement_1.pdf.

_ L. Ricciardulli, K. Hilburn, and C. Mears, 2007: How much more rain will global warming bring? Science, 317, 233-235, https://doi.org/10.1126/science.1140746.

Wodzicki, K. R., and A. D. Rapp, 2016: Long-term characterization of the Pacific ITCZ using TRMM, GPCP, and ERA-Interim. J. Geophys. Res. Atmos., 121, 3153-3170, https://doi.org/ 10.1002/2015JD024458.

Zhou, Y. P., K.-M. Xu, Y. C. Sud, and A. K. Betts, 2011: Recent trends of the tropical hydrological cycle inferred from Global Precipitation Climatology Project and International Satellite Cloud Climatology Project data. J. Geophys. Res., 116, D09101, https://doi.org/10.1029/2010JD015197. 